\title{
Ensaios experimentais de painéis de madeira de Pinus pinaster (Pinho bravo)
}

\section{Experimental tests of Pinho Bravo wood panels}

\author{
Pedro Gil Girão dos Santos ${ }^{1}$, Alfredo Manuel Pereira Geraldes Dias ${ }^{2}$, \\ Telmo Filipe Marques Morgado ${ }^{3}$ e Carlos Eduardo de Jesus Martins ${ }^{1}$
}

\begin{abstract}
Resumo
O presente trabalho é reflexo de um estudo exploratório experimental com vista à produção de painéis de madeira de Pinho bravo (Pinus pinaster) para fins construtivos. O produto em causa foi obtido pela colagem de camadas compostas por peças de madeira processada de seção retangular, ortogonalmente entre si, de forma a produzir os painéis. O produto em causa é similar à madeira laminada colada cruzada, no entanto a colagem entre camadas foi feita de uma forma linear e não sobre toda a superfície. $O$ módulo de elasticidade das peças foi estimado através de ensaios estático e dinâmicos, com uma boa correlação entre resultados. Os testes realizados aos painéis (um de três e outro de cinco camadas) consistiram em ensaios estáticos com vista a avaliar os módulos de elasticidade longitudinal e de cisalhamento. Os resultados revelaram uma menor rigidez nos painéis face à matéria-prima base e uma acentuada influência do corte na deformação bem como um comportamento não-linear dos painéis, fatos atribuídos à presença das camadas perpendiculares e à deformação no adesivo.
\end{abstract}

Palavras-chave: derivados de madeira, painéis de madeira, madeira de conífera, colagem de madeira

\begin{abstract}
The present work describes an experimental exploratory study with the aim of production of wooden panels of Pinho bravo (Pinus pinaster) for constructive purposes. The analyzed product was obtained by bonding layers composed of processed wood pieces with rectangular cross section, orthogonally to each other, to produce panels. The product in question is similar to cross laminated timber, but the bond between layers was made in a linear way and not over the entire surface. The modulus of elasticity of the pieces was estimated by static and dynamic tests, with a good correlation between results. The testing of panels (one with three and the other with five-layer) consisted of static tests to assess the longitudinal modulus of elasticity and shear. Results showed less stiffness in the panels against the raw material basis and a pronounced influence of shear on the deformation as well as a non-linear behavior of the panels, facts attributed to the presence of the perpendicular layers and deformation in the adhesive.
\end{abstract}

Keywords: wood products, coniferous wood, wood glue

\section{INTRODUÇÃO}

A madeira de Pinho bravo (Pinus pinaster) utilizada neste estudo é uma espécie resinosa largamente utilizada em Portugal na construção há já vários anos. (MORGADO et al., 2009), (MARTINS; DIAS, 2012), (MORGADO et al., 2013). Inúmeros estudos relativos à aplicação desta espécie para fins estruturais têm demonstrado a sua aptidão, inclusive a sua aplicação para diversas soluções construtivas, entre as quais estruturas mistas madeira-concreto (DIAS et al., 2010), (DIAS, 2012).

O produto em análise, devido à sua concepção, apresenta características muito semelhantes à da madeira laminada colada cruzada, no entanto existem diferenças no processo de produção, nomeadamente no processo de colagem, pois na madeira laminada colada cruzada essa colagem é feita em toda a superfície nas interfaces das camadas, enquanto no produto em causa essa colagem foi realizada de uma forma linear. Dada a semelhança existente com o laminado cruzado, foram os estudos realizados em relação a esse produto que serviram de base para o desenvolvimento do estudo exploratório.

\footnotetext{
${ }^{1}$ Mestre em Engenharia Civil . Universidade de Coimbra / Departamento de Engenharia Civil. Rua Luís Reis Santos - Pólo II 3030-788 - Coimbra, Portugal. E-mail: uc2006107489@student.uc.pt,

2Professor Doutor em Engenharia Civil Universidade de Coimbra / Departamento de Engenharia Civil. Rua Luís Reis Santos - Pólo II 3030-788 - Coimbra, Portugal. E-mail: alfgdias@dec.uc.pt

${ }^{3}$ Doutor em Engenharia Civil. Universidade de Coimbra / Departamento de Engenharia Civil. Rua Luís Reis Santos - Pólo II 3030-788 - Coimbra, Portugal. E-mail telmo.morgado@gmail.com
}

Sci. For., Piracicaba, v. 44, n. 109, p. 75-83, mar. 2016 DOI: dx.doi.org/10.18671/scifor.v44n109.07 
A madeira laminada colada cruzada, designada em inglês por cross-laminated timber (CLT), é um produto derivado de madeira, obtido pela colagem de lâminas em camadas perpendiculares entre si, de forma a produzir painéis de grandes dimensões. O fato de as camadas se encontrarem coladas e dispostas ortogonalmente confere aos painéis grande estabilidade dimensional e uma apreciável capacidade para suportar esforços nas duas direções ortogonais, o que conduz a um comportamento similar ao de uma laje. As lâminas que constituem cada camada, bem como as próprias camadas do painel são normalmente coladas entre si com recurso a colas à base de poliuretano ou resinas à base de formaldeído (CRESPELL; GAGNON, 2010). O número de camadas nos painéis varia normalmente entre 3 a 11 camadas, com espessuras de lâminas que vão sensivelmente dos 6 aos $45 \mathrm{~mm}$, e espessura total entre os 60 e os $300 \mathrm{~mm}$. Por sua vez as dimensões em planta dos painéis podem atingir cerca de $4 \mathrm{~m}$ de largura por $24 \mathrm{~m}$ de comprimento, estando estas medidas, a maior parte das vezes, limitadas não tanto por questões de fabrico, mas de transporte. A obtenção de painéis com grandes dimensões faz-se com recurso à técnica de finger-joint (FPL, 2010).

Atualmente devido à inexistência de normas específicas, as características dos produtos de CLT ainda não obedecem a uma normalização, como por exemplo a definição das classes de resistência. Os fabricantes têm por isso desenvolvido documentação própria, em que definem as propriedades relevantes ao projeto e dimensionamento estrutural dos painéis. No entanto estudos têm sido realizados com o intuito de avaliar o comportamento mecânico dos painéis. Baseando-se na norma EN 408 (CEN, 2003), referente à determinação de propriedades mecânicas em vigas de madeira, (STEIGER et al., 2012), compararam as propriedades elásticas obtidas por meio dessa norma com as obtidas através de uma análise dinâmica para painéis de CLT feitos de espruce. Os autores concluíram que a rigidez à flexão pode variar fortemente dentro de um único painel de CLT, sendo que essas variações dependem do grau de homogeneização do painel de CLT, i.e. quanto menores forem os componentes (lâminas) e quanto menores as variações das propriedades mecânicas (que podem ser alcançadas por uma adequada classificação da resistência da matéria prima) melhor se pode estimar a rigidez de flexão de painéis de CLT a partir de amostras em forma de tira retiradas dos painéis. (PARK et al., 2003) analisaram o desempenho à flexão de vigas laminadas coladas convencionais e cruzadas de diferentes espécies com vista a obter correlações entre os módulos de elasticidade e distorção obtidos nas vigas laminadas e os valores obtidos nas lâminas individuais que as constituíram. Concluíram que ao cruzar as camadas ao invés de os manter paralelos em relação ao vão da viga aumenta as propriedades perpendiculares ao vão da viga, nomeadamente o módulo de elasticidade e módulo de rotura, e que esse aumento é mais pronunciado ao adotar espécies de madeiras com densidades mais baixas. Não foi encontrada nenhuma correlação entre a elasticidade das lâminas individuais e as vigas laminadas cruzadas, fato atribuído à influência da deformação causada pela força de corte no módulo de elasticidade medido, sendo que a percentagem de deformação provocada pela força de corte versus a deformação total mostrou valores elevados (16,1\% a 40,5\%).

A inovação do produto em estudo justifica-se com o fato de não existirem quaisquer estudos relativos a painéis estruturais utilizando madeira de Pinho bravo. Pretende-se assim a avaliar o potencial desta espécie para aplicações estruturais segundo os modernos padrões de construção em madeira e ao mesmo valorizar um recurso que é atualmente, em grande parte, subaproveitado para produtos de baixo valor, como paletes ou pellets para aquecimento.

\section{MATERIAL E MÉTODOS}

\section{Descrição geral da matéria-prima utilizada}

A matéria-prima que serviu de base à constituição dos painéis analisados consistiu num total de 245 lâminas de madeira serrada de seção retangular de Pinho bravo (Pinus pinaster) que se subdividiu em dois grupos: $\mathrm{o} \mathrm{n}^{\mathrm{o}} 1$ constituído por 154 peças com dimensões nominais 2200x89x21 mm e o $\mathrm{n}^{\circ} 2$ constituído por 91 peças com dimensões nominais 2200x134x22 mm. Foram definidas estas dimensões por serem secções padrão muito usadas na indústria. 


\section{Classificação das lâminas: classificação visual}

A norma portuguesa NP 4305 (IPQ, 1995) estabelece regras específicas referentes à classificação visual de madeira de Pinho bravo. De acordo com a norma, podem ser definidas duas classes de qualidade: E e EE. Através da análise visual das lâminas, concluiu-se existir alguma heterogeneidade dentro do grupo das peças analisadas, resultando numa classificação indicativa das peças como E, EE ou ainda rejeição de determinadas peças, verificando-se, de um modo geral, a classe E como a mais predominante.

\section{Classificação das lâminas: ensaios dinâmicos}

Foram realizados ensaios dinâmicos às lâminas recorrendo ao dispositivo de classificação de madeira Timber Grader MTG (BROOKHUIS, 2009). O princípio de funcionamento do MTG baseia-se na medição da frequência fundamental de vibração da peça sujeita a um impulso longitudinal. A partir da frequência medida, e em combinação com as propriedades da peça (dimensões, massa e teor de água), é possível obter uma estimativa do módulo de elasticidade.

\section{Classificação das lâminas: ensaios estáticos não-destrutivos}

Seguiram-se as indicações da norma EN 408 (CEN, 2003) por forma a determinar o módulo de elasticidade global de cada lâmina. O ensaio de flexão a quatro pontos foi realizado aumentando a carga com um incremento constante (deslocamento vs tempo) até perfazer $40 \%$ da carga máxima de rotura prevista, obtendo-se o módulo de elasticidade a partir da regressão linear entre a carga aplicada e a deformação medida.

\section{Classificação das laminas: comparação de resultados}

Em ambos os ensaios (dinâmico e estático) foi previamente determinado o teor de água com recurso a um humídimetro de agulhas por forma a comparar valores dos módulos de elasticidade dinâmico e estático convertidos para a situação de referência, isto é, para um teor de água de 12\%, de acordo com a norma EN 384 (CEN, 2004). A correlação obtida entre módulos de elasticidade foi bastante elevada $\left(R^{2}=0,88\right.$ para o grupo $\mathrm{n}^{\circ} 1$ e $R^{2}=0,90$ para o grupo $\left.\mathrm{n}^{\circ} 2\right)$.

Por forma a ter uma amostra mais homogénea na constituição dos painéis, as lâminas que apresentaram módulo de elasticidade estático abaixo de $8 \mathrm{MPa}$ foram rejeitadas. Os valores médios obtidos para o módulo de elasticidade global para um teor de água de referência de $12 \%$ são apresentados na Tabela 1 .

Tabela 1. Valores médios de do módulo de elasticidade estático das lâminas. Table 1. Mean values of static modulus of elasticity of the boards.

\begin{tabular}{cc}
\hline Grupo & $\mathbf{E}_{\text {mean }}(\mathbf{M P a})$ \\
\hline 1 & 13752 \\
2 & 12830 \\
\hline
\end{tabular}

\section{Descrição dos painéis}

Após a caracterização das lâminas estas foram selecionadas aleatoriamente para criar dois painéis distintos: um de três camadas (painel A) e outro de cinco camadas (painel B) ambos com dimensões em planta de 2200mmx940mm (Figura 1).

O processamento de fabrico de cada painel consistiu em colar lateralmente as lâminas entre si por forma a criar as camadas constituintes, e em seguida colar essas camadas ortogonalmente entre si por forma a criar o painel, tendo-se utilizado uma cola à base de poliuretano. Imediatamente após a aplicação do adesivo e durante a sua cura, o painel foi prensado, permanecendo assim durante vinte e quatro horas.

Em ambos os painéis, a direção do fio das lâminas nas camadas exteriores foi orientada segundo o maior vão dos painéis (vão a ensaiar). Dado que as lâminas do grupo $\mathrm{n}^{\mathrm{o}} 1$ apresentavam melhor qualidade (maior módulo de elasticidade médio), foram colocadas nas faces exteriores enquanto as do grupo $\mathrm{n}^{\mathrm{o}} 2$ foram colocadas nas camadas interiores. 


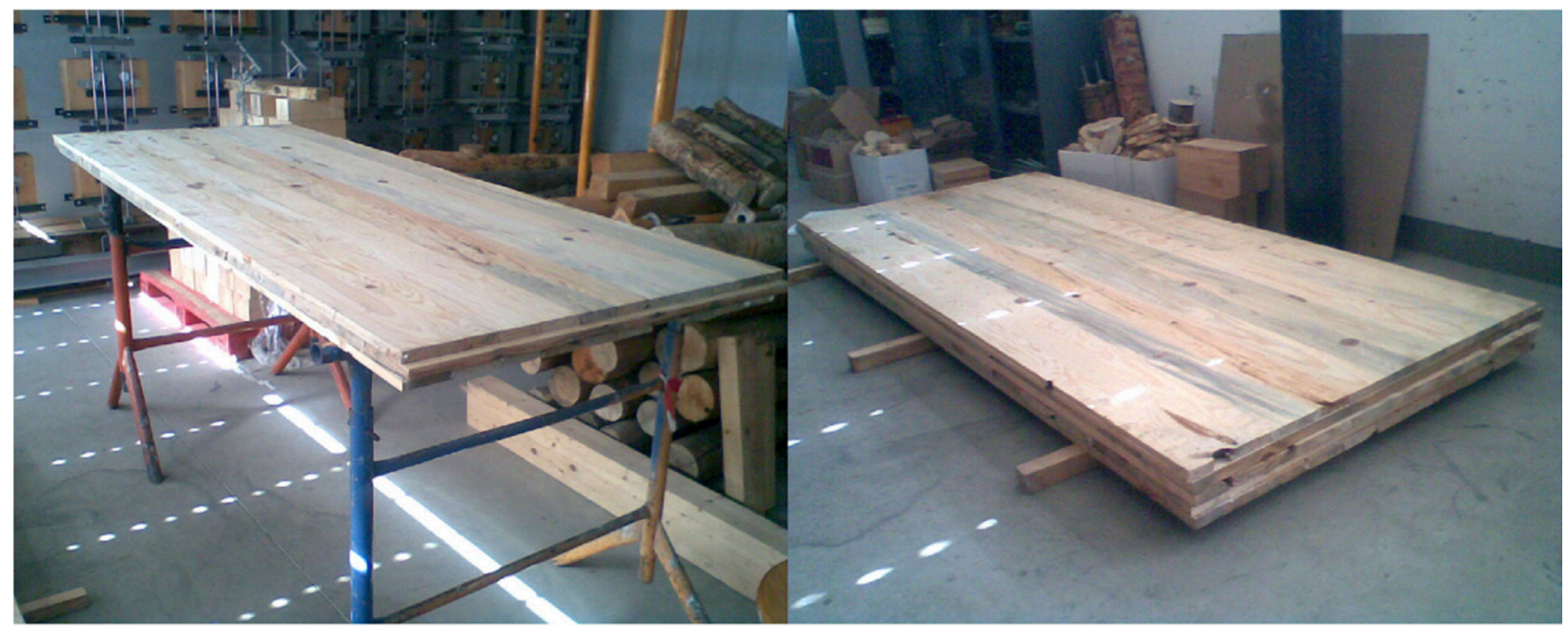

Figura 1. Painéis de madeira: painel $A$ (esq.) e painel $B$ (dir.).

Figure 1. Wood panels: panel A (left) and panel B (right).

\section{Ensaio estático não-destrutivo dos painéis}

Dadas as particularidades do produto em análise, e não havendo estudos específicos relativos ao mesmo, seguiram-se as metodologias experimentais adoptadas por outros autores para testes de CLT. Como tal seguiu-se a estratégia adotada por (STEIGER et al., 2011) e (PARK et al., 2003) que realizaram ensaios estáticos baseados nas especificações da norma EN408 para vigas maciças e laminadas. Da revisão bibliográfica foi possível entender que a deformação por corte é uma parcela bastante significativa na deformação deste tipo de painéis. Como tal, e sabendo que a deformação total numa viga solicitada no plano perpendicular é obtida em função dos módulos de elasticidade e de distorção, foram essas duas propriedades elásticas que se procuraram definir com base nos ensaios realizados.

\section{Determinação do módulo de elasticidade}

A norma EN408 apresenta dois parâmetros relacionados com o módulo de elasticidade: o módulo de elasticidade local $(E m, l)$ e o global $(E m, g)$. Ambos são determinados com base num mesmo esquema de ensaio estático à flexão a quatro pontos, no entanto as deformações apesar de ambas serem medidas a meio vão, têm como referência pontos distintos. No local, a deformação é medida em relação a uma zona dentro do terço central do painel, entre as cabeças de carga sujeita à flexão pura; no global, a deformação é medida em relação aos apoios (vão total) e como tal sujeito à ação conjunta do momento fletor e do esforço de corte. Assim sendo, a comparação entre estes dois módulos permite perceber a influência da deformação por corte na deformação total, isto é, quanto maior for a diferença entre os módulos local e global, maior será a contribuição do corte. O esquema de ensaio adotado para determinação de cada parâmetro é mostrado nas Figuras 2 e 3.
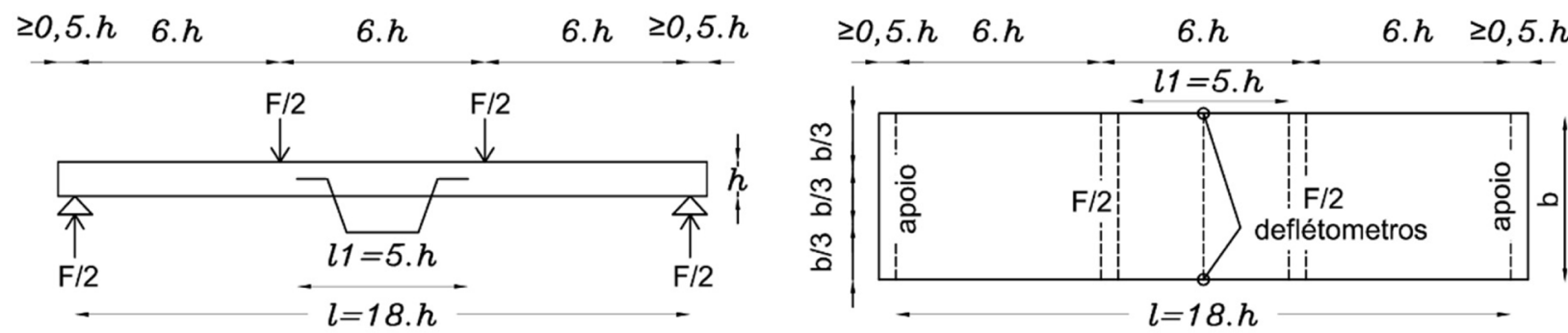

Figura 2. Esquema de ensaio para determinação do módulo de elasticidade local. Vista em perfil (esq.) e em planta (dir.). Figure 2. Test arrangement for determining the local modulus of elasticity. Profile view (left) and top view (right).

Em ambos os casos a carga foi aplicada ao longo da largura do painel e nos terços do vão ( $a=$ l/3). A carga $(F)$ a aplicar não deverá ser superior a $40 \%$ da carga máxima estimada, por forma a não introduzir deformações permanentes no elemento estrutural. 

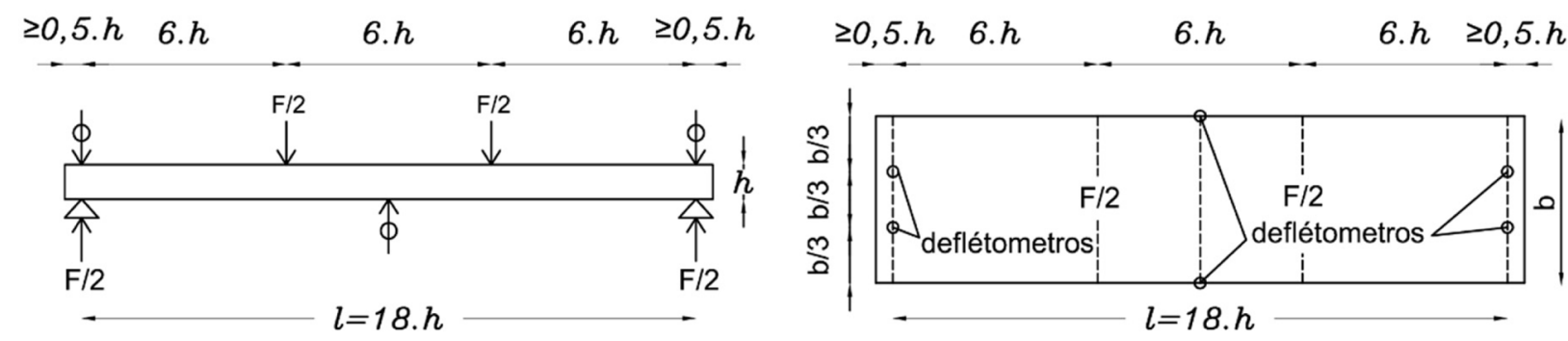

Figura 3. Esquema de ensaio para determinação do módulo de elasticidade global. Vista em perfil (esq.) e em planta (dir.). Figure 3. Test arrangement for determining the global modulus of elasticity. Profile view (left) and top view (right).

No caso do módulo de elasticidade local, a deformação $(w)$ foi medida através de dois defletómetros colocados a meia altura da seção em cada face lateral do painel com os eixos fixos nos extremos da distância $l_{1}=5 h$, tal como é exigido pela norma. Através da medição das deformações em função da carga aplicada é possível efetuar uma regressão linear e assim determinar o módulo de elasticidade local:

$$
E_{m, l}=\frac{a l_{1}^{2}\left(F_{2}-F_{1}\right)}{16 . I\left(w_{2}-w_{1}\right)}
$$

Em que: $I$ - momento de inércia da seção transversal, $F_{2}-F_{1}$ - incremento de carga da regressão linear com coeficiente de correlação igual ou superior a $0.99, w_{2}-w_{1}-$ incremento de deformação em $\mathrm{mm}$ correspondente ao intervalo de $F_{2}-F_{1}$.

No caso do módulo de elasticidade global, a deformação foi medida colocando dois defletómetros a medir na face tracionada do painel e espaçados a 1/3 da largura do mesmo. Adicionalmente foi também medido o esmagamento nos apoios, através da colocação de dois defletómetros por apoio, obtendo-se a deformação global através da diferença entre a deformação medida a meio vão e o esmagamento registado nos apoios. O módulo de elasticidade global foi determinado de acordo com:

$$
E_{m, g}=\frac{l^{3}\left(F_{2}-F_{1}\right)}{b h^{3}\left(w_{2}-w_{1}\right)}\left[\left(\frac{3 a}{4 l}\right)-\left(\frac{a}{l}\right)^{3}\right]
$$

\section{Determinação do módulo de distorção}

A EN 408 prevê dois métodos para a avaliar o módulo de distorção $(G)$ : o método do vão único e o método do vão variável. O método do vão único envolve a determinação do módulo de elasticidade local $(E m, l)$ e o módulo de elasticidade aparente $(E m, a p p)$. Este último é determinado de forma similar ao global, mas considerando um vão $l=5 h$ e a carga aplicada a meio vão de acordo com o esquema indicado na Figura 4.
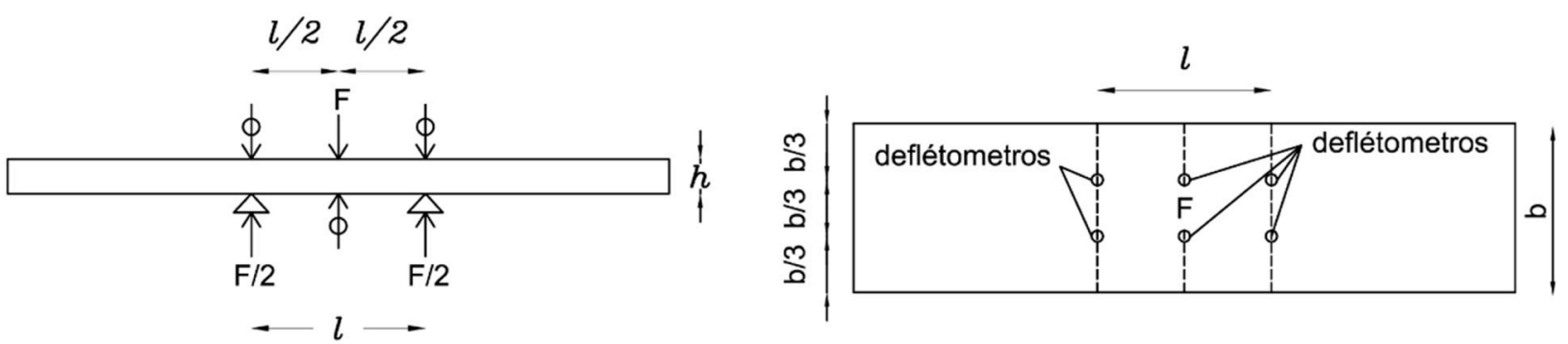

Figura 4. Esquema de ensaio para determinação do módulo de elasticidade aparente. Vista em perfil (esq.) e em planta (dir.).

Figure 4. Test arrangement for determining the apparent modulus of elasticity. Profile view (left) and top view (right).

O módulo de distorção $(G)$ é dado por:

$$
G=\frac{k_{G} h^{2}}{l_{1}{ }^{2}\left[\frac{1}{E_{m, a p p}}-\frac{1}{E_{m, l}}\right]}
$$

Em que: $h$ - altura da seção transversal, $k G=1.2$ para secções retangulares.

Segundo a EN408, o método do vão variável envolve a determinação do módulo de elasticidade aparente $\left(E_{m, a p p}\right)$ para um conjunto de pelo menos quatro vãos para uma mesma peça. Esses vãos de- 
verão ter um incremento $(h / l)^{2}$ aproximadamente igual entre eles e que deverá estar compreendido no intervalo [0.0025 - 0.035]. No entanto, devido a limitações de tempo para ensaio laboratorial, nos ensaios realizados apenas se consideraram dois vãos $(l=2.5 \mathrm{~h}$ e $l=18 \mathrm{~h})$, sendo que o último está fora dos limites do referido intervalo.

Fazendo uma regressão linear no gráfico $(h / l)^{2} /\left(1 / E_{m, a p p}\right)$ é possível determinar o módulo de distorção a partir do declive da reta de regressão:

$$
G=\frac{k_{G}}{k_{1}}
$$

Em que: $k_{1}$ - declive da reta de regressão.

A norma refere ainda que para este método é possível obter um valor para o módulo de elasticidade, dado pelo inverso do valor da ordenada da reta na origem:

$$
E_{m}=\frac{1}{k_{2}}
$$

Em que: $k_{2}$ - ordenada na origem da reta de regressão.

\section{Ensaios estáticos destrutivos}

Para a determinação da carga de rotura seguiu-se o procedimento indicado na EN 408, usando o mesmo esquema que para o módulo de elasticidade global, mas aplicando a carga a um ritmo constante de forma a atingir a rotura em 300+/-120 segundos, registando a carga aplicada a cada instante e medindo o deslocamento vertical no atuador de carga.

\section{RESULTADOS E DISCUSSÃO}

A comparação dos valores obtidos para o $E m, l$ com os obtidos para o $E m, g$ para cada painel (Tabela 2), demonstra uma diferença significativa entre valores para o painel A (30\%) e bastante pronunciada para o painel B (56\%). As diferenças encontradas são, portanto, um forte indicio da influência do corte na rigidez global dos painéis, já que o módulo de elasticidade global (o qual é calculado tendo em conta os esforços de flexão e corte) se mostrou muito abaixo do local (calculado tendo em conta a flexão pura no terço central do vão). É de notar também que os valores obtidos são bastante inferiores aos da matéria prima que lhes deu origem (Tabela 1).

Tabela 2. Módulos de elasticidade global e local e diferença percentual entre ambos os painéis.

Table 2. Global and local elasticity modules and percentage difference between the two panels.

\begin{tabular}{lccc}
\hline & $\mathrm{E}_{\mathrm{m}, \mathrm{l}}(\mathrm{MPa})$ & $\mathrm{E}_{\mathrm{m}, \mathrm{g}}(\mathrm{MPa})$ & $\left|\mathrm{E}_{\mathrm{m}, \mathrm{1}}-\mathrm{E}_{\mathrm{m}, \mathrm{g}}\right| / \mathrm{E}_{\mathrm{m}, \mathrm{g}}(\%)$ \\
\hline Painel A & 7757 & 5952 & $30 \%$ \\
Painel B & 5023 & 3220 & $56 \%$ \\
\hline
\end{tabular}

Os valores obtidos para o $E_{m, a p p}$ para cada um dos vãos considerados $(l=2.5 \mathrm{~h}$ e $l=18 \mathrm{~h})$ e o correspondente valor de $G$ obtido por ambos os métodos, bem como o valor do módulo de elasticidade $\left(E_{m}\right)$ estimado pelo método do vão variável, são apresentados na Tabela 3.

Tabela 3. Módulos de elasticidade aparente e de distorção obtidos pelos métodos do vão único e variável.

Table 3. Apparent elasticity and distortion modules obtained by the methods of single and variable span.

\begin{tabular}{lcc|c|cc}
\hline & \multicolumn{2}{c|}{$\mathbf{E}_{\mathbf{m}, \text { app }}$ (MPa) } & Método do Vão Único & \multicolumn{2}{c}{ Método do Vão Variável } \\
& I=5.h & I=18.h & G (MPa) & G (MPa) & $\mathbf{E}_{\mathbf{m}}$ (MPa) \\
\hline Painel A & 1197 & 4276 & 69 & 74 & 5360 \\
Painel B & 417 & 3933 & 22 & 21 & 15400 \\
\hline
\end{tabular}

Como se pode verificar, para ambos os painéis, obteve-se um valor do módulo de distorção consistente com ambos os métodos usados (vão único e vão variável). Tal como para o módulo de elasticidade, os valores obtidos foram baixos, indicio da grande susceptibilidade à deformação por corte dos painéis. Para o painel A, a estimativa do módulo de elasticidade, Em, dada pelo método do vão variável (5360 MPa), mostrou-se muito próxima do valor obtido para o módulo de elastici- 
dade global (5952 MPa). No painel B o valor de Em obtido (15400 MPa) já se revelou muito acima do valor de $E m, g$ (3220 MPa), fato que poderá estar relacionado com a adoção de apenas dois vãos de ensaio, o que conduz a uma regressão linear com dois pontos apenas, quando a norma exige o mínimo de quatro.

Há que referir, que a baixa rigidez obtida, estará não só relacionada com a deformação nas laminas paralelas ao eixo de flexão, mas também na deformação do adesivo de colagem, já que este foi aplicado de forma linear e não em toda a superfície de madeira, e logo sujeito a tensões de cisalhamento superiores, já que para a mesma força, a superfície de contato é inferior.

Tendo em conta os baixos valores obtidos nos parâmetros caraterizadores da rigidez do painel é possível constatar que, e ao contrário dos tradicionais produtos derivados de madeira (como vigas maciças ou laminadas), a deformação devido ao corte é uma parcela importante na deformação total no painel, não devendo, portanto, ser desprezável aquando do dimensionamento deste tipo de produto. Assim, para além do módulo de elasticidade longitudinal, o módulo de cisalhamento será um parâmetro de referência obrigatório na caracterização deste tipo de produto.

Nas Figuras 5 e 6 são apresentados os gráficos força/deslocamento obtidos nos ensaios de rotura dos painéis. O deslocamento medido corresponde ao deslocamento global medido pelo atuador de carga. Em ambos os gráficos se denota na fase inicial um patamar que se pode considerar linear (até cerca de $20 \mathrm{~mm}$ de deformação no painel A e $25 \mathrm{~mm}$ no painel B), sendo que a partir daí a rigidez varia não-linearmente.

Observando a Figura 5 referente ao gráfico força/deslocamento do painel A, são claramente identificáveis dois pontos de quebra abrupta na rigidez do painel a cerca de 84 e $88 \mathrm{kN}$ de força. Essas descontinuidades correspondem a pequenas roturas localizadas que ocorreram devido ao corte nas laminas a $90^{\circ}$ (corte planar). A carga máxima atingida de $92.4 \mathrm{kN}$ correspondeu a rotura por flexão ocorrida a sensivelmente meio vão, na camada inferior do painel sujeita aos maiores esforços de tração. Também no gráfico força/deslocamento do painel B (Figura 6) são claramente identificáveis três pontos em que a rigidez diminui abruptamente (quando a força é de 56, 59 e $78 \mathrm{kN}$ aproximadamente). Tal como no painel A, estes pontos correspondem as roturas localizadas por corte nas lâminas a $90^{\circ}$. A carga máxima atingida de $81.3 \mathrm{kN}$ correspondeu à rotura geral do painel por corte planar ocorrida nas laminas a $90^{\circ}$. Em ambos os painéis, as roturas por corte planar ocorreram nas zonas entre um dos apoios e o ponto de aplicação de carga mais próximo, ou seja, nas zonas onde o esforço de corte atua.

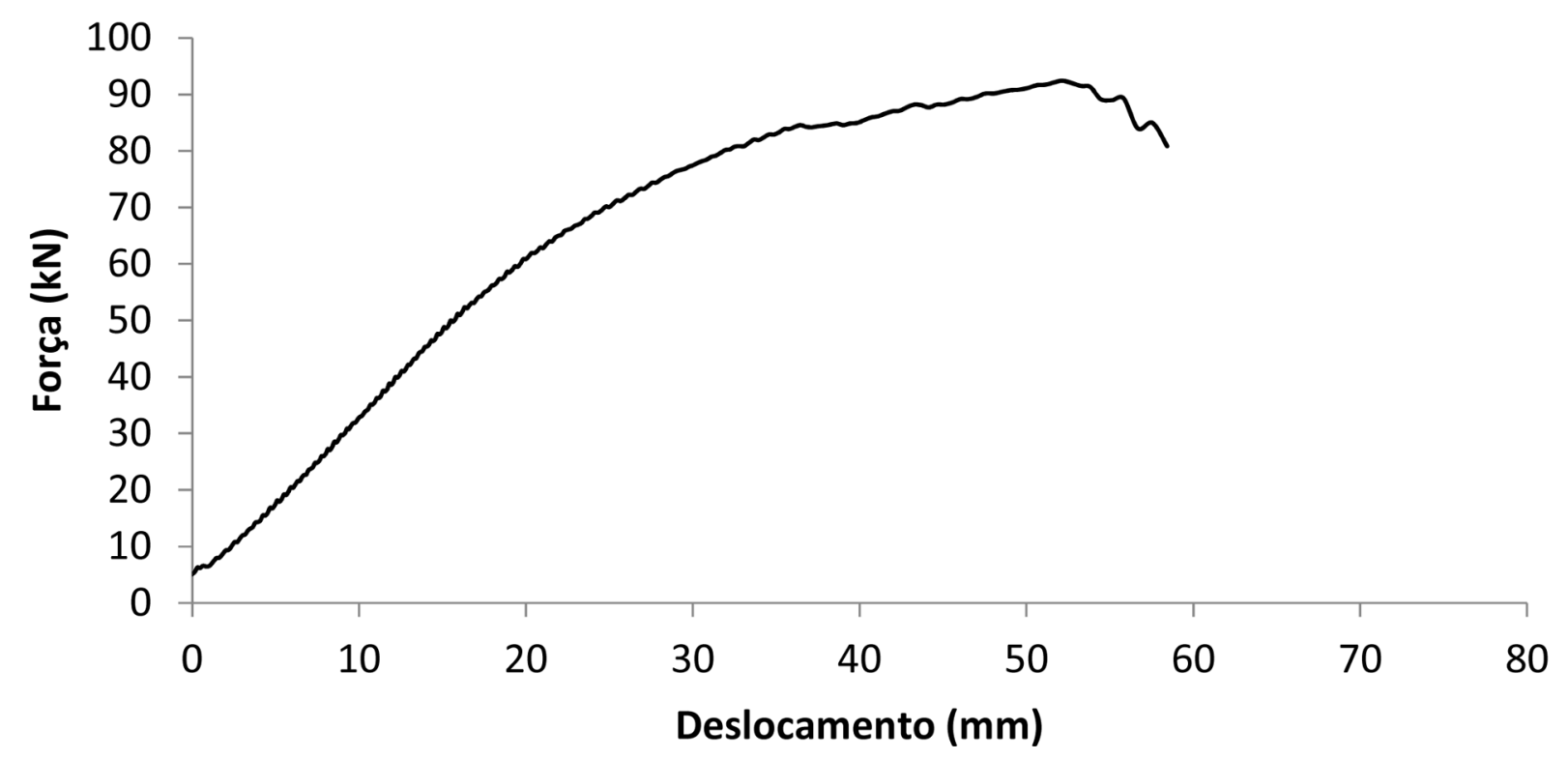

Figura 5. Gráfico força/deslocamento do ensaio de rotura - painel A.

Figure 5. Force/displacement plot of the breaking test - panel A. 


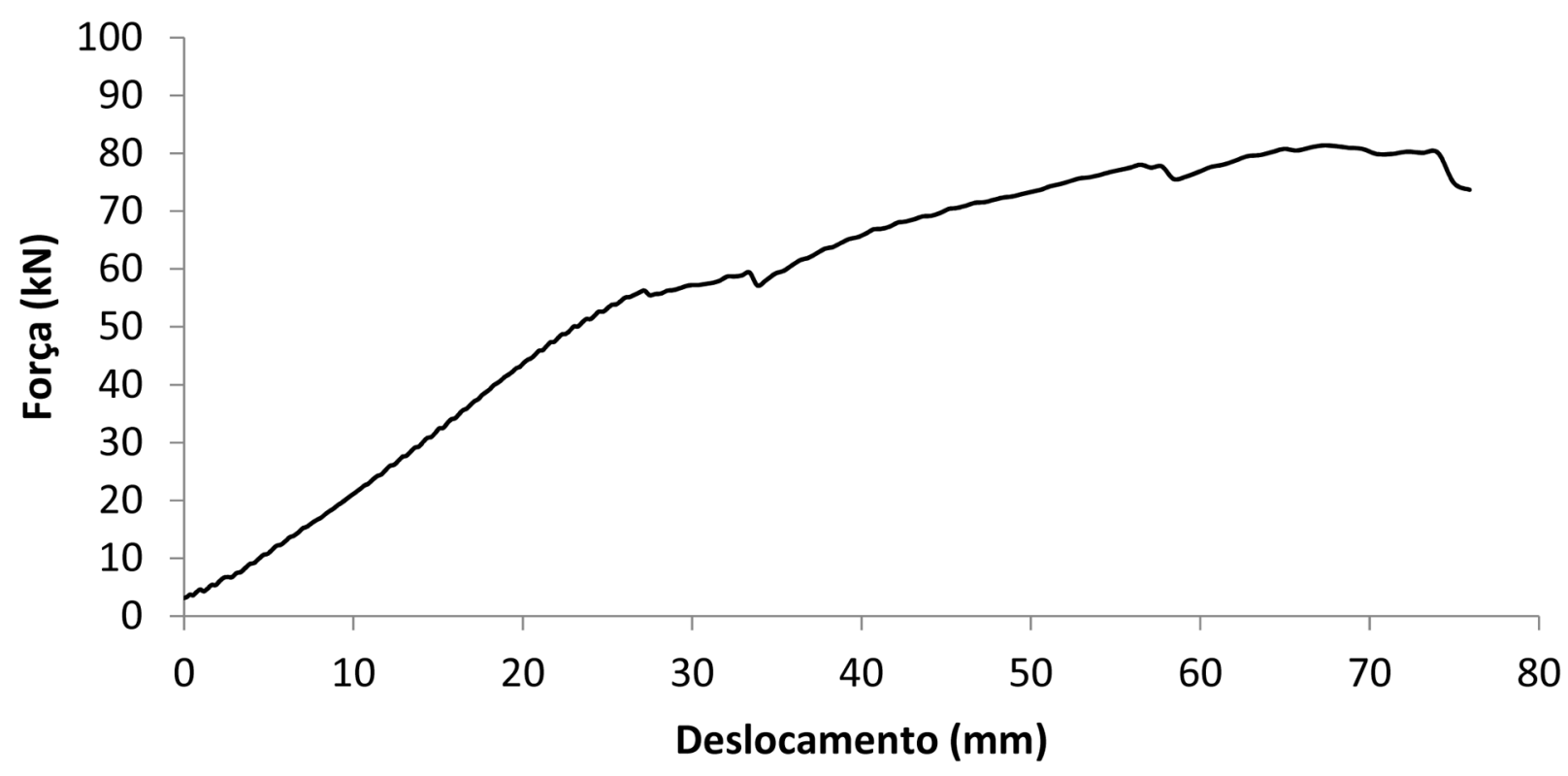

Figura 6. Gráfico força/deslocamento do ensaio de rotura - painel B.

Figure 6. Force/displacement plot of the breaking test - panel B.

O comportamento não-linear observado, poderá advir não só de uma possível deformação plástica no adesivo, mas também, e em consequência disso e da deformação por corte, da própria distribuição e geometria de forças aplicadas no painel, já que a partir de certo patamar de carga, a deformada nos painéis é bastante acentuada, deixando de fazer sentido uma análise linear de distribuição de tensões como a que é preconizada na norma EN 408.

\section{CONCLUSÕES}

Neste estudo exploratório foi possível aferir o potencial da madeira de pinho bravo para a produção de painéis. Ficou também patente a importância da deformação por corte neste tipo de produto com camadas ortogonais. A elevada deformação observada poderá ser atribuída não só à deformação por corte, que terá ocorrido maioritariamente nas camadas cujo fio é perpendicular ao do vão de ensaio, mas também à própria adesão entre camadas, que foi feita de uma forma linear e não em toda a superfície, estando, portanto, sujeita a maiores esforços. Assim sendo, uma colagem eficaz poderá ser decisiva num melhor comportamento deste tipo de painéis a solicitações perpendiculares ao seu plano, tirando assim melhor partido do significativo potencial da matéria prima estudada para esta aplicação.

\section{REFERÊNCIAS BIBLIOGRÁFICAS}

BROOKHUIS. Timber grader MTG manual Help. Brookhuis Micro-Electronics BV. 2009.

CEN - EUROPEAN COMMITTEE FOR STANDARDIZATION. EN 384: Structural timber - Determination of characteristic values of mechanical properties and density. Brussels, 2004.

CEN - EUROPEAN COMMITTEE FOR STANDARDIZATION. EN 408: Timber Structures - Structural timber and glued laminated timber - Determination of some physical and mechanical properties. Brussels, 2003.

CRESPELL, P.; GAGNON, S. Cross Laminated Timber: a Primer. FP Innovations. 2010.

DIAS, A. M. P. G. Analysis of the Nonlinear Behavior of Timber-Concrete Connections. Journal of Structural Engineering, v. 138, n. 9, p. 1128-1137, 2012. 
DIAS, A. M. P. G.; VAN DE KUILEN, J. W.; CRUZ, H. M. P.; LOPES, S. M. R. Numerical Modeling of the LoadDeformation Behavior of Doweled Softwood and Hardwood Joints. Wood and Fiber Science, Madison, v. 42, n. 4, p. 480-489, 2010.

FPL - FOREST PRODUCTS LABORATORY. Wood handbook - Wood as an engineering material. Madison: USDA Forest Service, 2010. 508 p. (FPL General Technical Report, 190).

IPQ - INSTITUTO PORTUGUÊS DE QUALIDADE. NP 4305:1995. Madeira serrada de pinheiro bravo para estruturas. Classificação visual. 1995.

MARTINS, C.; DIAS, A. Bending Strength and Stiffness of Portuguese Maritime Pine Utility Poles. Forest Products Journal, Madison, v. 62, n. 2, p. 114-120, 2012.

MORGADO, T. F. M.; DIAS, A. M. P. G.; MACHADO, J. S.; NEGRÃO, J. H. Structural Connections for SmallDiameter Poles. Journal of Structural Engineering, v. 139, n. 11, p. 2003-2009, 2013

MORGADO, T. F. M.; RODRIGUES J.; MACHADO, J. S.; DIAS, A. M. P. G.; CRUZ, H. Bending and compression strength of Portuguese Maritime pine small-diameter poles. Forest Products Journal, Madison, v. 59, n. 4, p. 23-28, 2009.

PARK, H.; FUSHITANI, M.; SATO, K.; KUBO, T.; BYEON, H. Static bending strength performances of crosslaminated woods made with five species. Journal of Wood Science, Amsterdam, v. 49, n. 5, p. 411-417. 2003.

STEIGER, R.; GÜLZOW, A.; CZADERSKI, C.; HOWALD, M.; NIEMZ, P. Comparison of bending stiffness of cross-laminated solid timber derived by modal analysis of full panels and by bending tests of strip-shaped specimens. European Journal of Wood and Wood Products, Berlin, v. 70, n. 1, p. 141-153, 2012.

Recebido em 21/04/2015

Aceito para publicação em 30/07/2015

Sci. For., Piracicaba, v. 44, n. 109, p. 75-83, mar. 2016

DOI: dx.doi.org/10.18671/scifor.v44n109.07 
